Roth, W.-M. (in press). Working out the interstitial and syncopic nature of the human psyche: On the analysis of veribal data. Integrative Psychological and Behavioral Science.doi: 10.1007.10s1112124-014-9259-1

\title{
Working out the Interstitial and Syncopic Nature of the Human Psyche: On the Analysis of Verbal Data
}

\begin{abstract}
Psychology studies the human mind and its development. Although it is often recognized that the human mind needs to be understood as a temporal (developmental) phenomenon between past and future and at the interstices between the idealities of pure Self and Other, the analytic methods interpretive researchers use tend to reify ahistorical and solipsist conceptions of the human being. In this article, I provide examples of an approach to the analysis of verbal data that immediately gets us to the interstitial and syncopic nature of the human psyche.
\end{abstract}

\begin{abstract}
Keywords Data analysis $\bullet$ Time $\bullet$ Development $\bullet$ Self $\bullet$ Other $\bullet$ Boundary $\bullet$ Syncope • Interstice
\end{abstract}

Our interfacing psyche constantly work on the frontier of personal and external world and on the past and future (constantly dealing with the uncertainty of the future). (Marsico \& Valsiner, in press)

Psychology evolved from a philosophical interest-e.g., Aristotle's Peri Psykhe [De anime] - to a science geared toward understanding the human condition generally and the human mind specifically. Consistent with philosophical analyses that emphasize the interplay of Self and Other (Marx/Engels, 1958) as well as the interplay of past and future (Bergson, 1908), recent theoretical work in psychology points to the person as a process coordinating "two oppositional mutually linked pairs": (a) past and future infinities and (b) inner and outer infinities (Marsico \& Valsiner, in press). All too often, however, psychological research reifies the opposition between inner versus outer and evacuates time from theoretical constructs, thereby mystifying temporal phenomena such as learning (Lave, 1993). To create an appropriate theory of the person, however, we need to understand that "the very existence of the mind is possible only at the borderline where there is a continual coming and going of one into the other, at the dynamic interface, as it were" (Mikhailov, 2001, p. 20, original emphasis). The interface between self and other is the product of a single, temporal and temporalizing process of "their mutual generation and mutual determination" (p. 21). To make this process salient, however, requires a particular attention to the ways in which human relations (e.g., in conversations) unfold and are both premised by and produce the distinctions between people. In this essay, I present a way of working with transcriptions that make visible the coordinating work that links the oppositional pairs of past | future and Self | Other.

\section{The Present as Syncope Between Past and Future Infinities}


As to psychical life unfolding underneath the symbols that conceal it, one readily perceives that time is its very stuff. (Bergson, 1908, p. 4)

Philosophers have recognized long ago that time and temporality are at the heart of the human condition (e.g., Bergson, 1908; Heidegger, 1977; Nietzsche, 1954). Psychologists, too, show an apparent interest in temporal phenomena-e.g., learning and development-but their analytic methods (minimal units of analysis) and theoretical categories do not contain time as an internal feature (Roth, 2013b). If we are interested in temporal phenomena that many psychologists target in their investigations then we need categories and minimum units of analysis appropriate to the phenomena. A minimal unit of learning or development has to contain time and change, which is different from theorizing learning and development as phenomena that happen in time. In this section, examples are provided of how the temporal aspects of human activity are deleted and how they might be emphasized in and through the analytic stance of the researcher.

\section{The Missing Future}

The future, as the past, is central in the human experience of time and temporality (Tateo \& Marsico, 2013). However, in much of psychological and other social science research, the future does not exist in the way it actually appears in human experience (Roth, 2013b). Rather than constituting an open horizon of possibilities (Mead, 1932), the future is closed by the analytic method, which makes human agents simply reify predetermined structures of events. Common approaches to the analysis of data, such as face-to-face conversations, fail to acknowledge that we live infinitely between two finalities (Marsico \& Valsiner, in press): on the frontiers between the inner (personal) and outer (external) world, on the one hand, and the factual past and uncertain future, on the other hand. As an entry point into the issues at the heart of this paper, consider the following excerpt from a conversation and how researchers typically analyze such data even when they avow cultural-historical and transactional theories of being, knowing, and learning. The 6-7 year-old children of a Swedish elementary class had been asked, as part of their homework, to test the solubility of substances. The teacher and seven students were seated around a circular table in a small space next to the classroom. We enter the situation while the teacher is speaking:

\section{Fragment 1}

1 Teacher: then I thought that we'd begin listening to Jessica. you're going to tell how it went at your home when you did your homework

2 Jessica: yes, it went like really good

3 Teacher: think about speaking so that this is heard now here

4 Jessica: yes ehum $\mathrm{f}$ food 
The researchers write that "in turn 1 the teacher prefaces the upcoming story," which "must be 'tellable' and this tellability usually appears in the preface" (Andrée et al., in press). As a result, "the coming story is defended as relevant and newsworthy." Here, the researchers describe turn 1 as "prefacing" an "upcoming story." Yet even if the teacher had the unarticulated intent of encouraging the student to tell a story, she cannot know in this situation whether a story will in fact be told. Saying that an upcoming story is prefaced imports into the analysis knowledge of what subsequently has happened. The analysis therefore is circulatory: an outcome, the telling of the story, is used to explain what has happened before (i.e., the prefacing of a story). However, what will have happened subsequently, a historical fact in some indeterminate future, is unavailable to the teacher and her students while the words of turn 1 unfurl from her lips. In fact, the future is open to such an extent that the teacher cannot even know when and how her own saying will end, and, therefore, what she will have said when her saying actually rather than presumedly comes to a close. This is evident in Fragment 2, which will have been the conclusion of Jessica's turn at talking about the experiments she conducted at her home. Following Jessica's turn 49, which itself followed an exchange about some substance that did not work, states that she took something away when it did not fit-leaving open what the referent of the fit was to be. In the reply, there is first the acknowledging adverb "okay," followed by a statement that the transcriber heard as a question, as indicated by the question mark. But did this statement move the event forward as if a question had occurred?

\section{Fragment 2}

49 Jessica: yes I took like after if from that there if it wouldn't fit.

$\rightarrow 50$ Teacher: okay, but did you try any more things than those that you told $\rightarrow$ about now? did you try any other things also? no.

51 Teacher: Leon. then let me hear how you had it at your home when you did the homework

The transcription continues as if there had been no pause-an aspect often omitted during transcription. If there had been a pause, such as in the following example of how the situation might have happened, could then hear the statement as an offer of a question.

\section{Fragment 3}

50 Teacher: okay, but did you try any more things than those that you told about now?

$\rightarrow 50 \mathrm{a} \quad(2.0 \mathrm{~s})$

$50 \mathrm{~b} \quad$ did you try any other things also?

$\rightarrow 50 \mathrm{c} \quad(1.5 \mathrm{~s})$

50s no.

$\rightarrow 50 \mathrm{c} \quad(1.0 \mathrm{~s})$

51 Teacher: Leon. then let me hear how you had it at your home when you did the homework 
These pauses would have to be part of a hearing and reading of the events. The teacher might have had the intent to ask a question (an illocutionary act), which would have been reified as such if the effect had been a reply. But here, there is no reply (turns 50a). Instead, the teacher continues (turn 50b). Thus, even if she had intended Jessica to respond and, therefore, considered the "now" (turn 50) to be ending her turn, the non-reply opens up the possibility for the teacher to continue to speak by taking another turn at talk. That is, at the instant that the "now" has come from her lips, the teacher could not know who would be speaking next and what she would be saying after what will have been a pause and a possibility for Jessica to speak that was not taken. In Fragment 2, the statement grammatically has the form of a question. However, in everyday conversations statements end up function like questions even though grammatically there is none. In fact, both Vygotskij (2005) and Vološinov (1930) use the same literary example to show that the same wordpronounced six times in a row by different speakers-was used to say six different things.

Returning to the reading of Fragment 1, the last word is "food" (turn 4). There is no punctuation to provide the analyst with a clue of what the transcriber might have heard. If the intonation had been strongly rising, the transcriber might have put "food?" whereas she would have put a period if the intonation had been strongly falling. A comma or semicolon might have appeared in the transcript if the intonation had been falling only slightly, so that an unfinished statement could be heard, especially when the speaker continued following a more or less extended pause. Each case would lead us to a hear a different action-e.g., "food?" may function as on offer of a reply and a query (glossed as "Is this the answer you are looking for?") simultaneously.

Thus, nobody — neither participant nor analyst — can know whether a story will in fact be coming forth at the instant of the teacher's speaking in turn 1 . The turn creates an open space of possibilities for next turns without determining and delimiting precisely what will come next (Roth, 2013b). The teacher produces a statement that can be heard as an instruction to what is to be happening next: "you're going to tell how it went at your home when you did your homework" (turn 1). We may represent this situation in the form of a cone of possible continuations (Figure 1a). Jessica does indeed speak, taking up in her statement a part of the preceding statement, "it went" and then concludes with a phrase that can be heard as a reply to a query initiated by the "how" (turn 1). That is, Jessica said "it went like really good." We therefore can hear the turn sequence as realizing a query | answer pair, which, from the open horizon of possible continuations will have selected one (Figure 1b). This turn pair now constitutes a historical fact that has implications for what can or has to occur next.

\section{««《«" Insert Figure 1 about here »"»»»»}

The same case can be made for the authors' claim that the story to come must be "tellable" and that this "tellability" must occur in some preface. This analysis presupposes that whatever will have been said and done was a tellable story, when in fact there are many things that might happen preventing intelligibility as a story. Moreover, a preface is part of a whole, such as the preface in a book, an abstract in a research article, or the title. In all these instances, the part is inside and outside 
simultaneously. Inside and outside are not appropriate categories for the analysis. This is so because an abstract is an abstract of the text that follows, but the two parts constitute the article as a whole. Thus, an abstract is part of a whole that reflects this whole, just as the title is part of the article while reflecting the contents of its main part (the report) and, therefore, also the contents of the abstract. Because whatever comes is still in the making when the teacher is speaking in turn 1 , we cannot say that she is prefacing whatsoever. This would be the kind of causal reasoning that not only fails to account for the contingent emergence of cultural and individual (developmental) change but also has been subject to critique by a wide range of pragmatic and phenomenological philosophers (e.g., Mead, 1932; Romano, 1998) analyzing the weaknesses of the metaphysical approach to understanding the human condition, history, psychology, and sociology.

\section{Neglect of the Possible}

Before continuing with the analysis, however, let us consider some other possibilities that can be observed in concrete lessons with children of the same age (e.g., Roth, 2011a). The intended addressee might not say anything at all or make some statement including "I don't know," "Why do you pick on me?," "I don't feel well," or "Could someone else take a turn?" Each of these statements would constitute a different continuation in Figure 1a and, retrospectively, constitute a different historical fact in Figure 1b. The possible turn sequences could then be heard as invitation | request for someone else to take a turn, invitation to take a turn | excuse for not wanting to take a turn ("I don't feel well"), as an instance of a student being picked upon, and so on. That is, the very ontological nature of turn 1 is at stake. The preceding examples show that it is not the teacher who determines the nature of her statement, although, from her perspective, there might have been an intent underlying a statement. But from the perspective of the listener, something else has been heard. This hearing is indexed by the second turn. Almost all of research in the social sciences conflates attributed or claimed speaking intents with the effect of a statement on the unfolding situation. A word, however, does not just emerge from the resonating cavities and vocal cords of the speaker but-almost simultaneously-resonates in the moving parts of the ear of the listener. Word and statements, therefore, have to be understood as multiplicities (Vološinov, 1930)made visible in Figure 1 as future possibilities - until their effect allows an attribution of the cause and becomes a historical fact. Thus, if Jessica had said, "Why do you pick on me?," the space of possible and socially necessary next actions would be different than they were when she said "it went like really good."

With this statement, a new intersubjective (historical) situation has been fixed (see solid lines and circles in Figure $1 \mathrm{~b}$ ), constituting a new future horizon and a new past that the next turn has to take into account. That is, any next turn not only constitutes a reaction to the preceding statement but reaches further into the past, such as would be the case were the teacher to reply "I never pick on students" or "I meant to give you an opportunity" to the statement "Why do you pick on me?" The teacher follows the actual statement by saying "think about talking so it sounds now in here." The statement can be heard as a request-reified as such by the next 
turn-for an elaboration of what Jessica has done or worked with. That is, although Jessica has replied to the preceding turn by directly picking up on and addressing a pertinent issue-how it went-the current statement (turn 3) requests to "think about speaking" so (i.e., in order to) make it hearable now, in the situation ("here"). That is, the request for using a form of talk so that it makes something sound in the here-and-now of the situation implies that this form of talk has not yet occurred-if it had occurred, the teacher would have been stating the obvious. The statement that can be heard as a request for a certain form of talk also constitutes an evaluation that what has occurred so far does not meet the expectation explicit or implied, in the request to talk about "how it went at [Jessica's] home."

\section{The Syncopic Nature of the Present: At the Intersection of Factual Pasts and Possible Futures}

Figure 1 shows how an actual conversation unfolds always against an infinite horizon of an open future and against an infinite horizon of the past. But rather than taking every instant of an event of interest, researchers, such as those interpreting the exchange between Jessica and her teacher, read the conversation backward from the perspective of the historically completed path. They then describe the situation as if there had been a necessary unfolding from the teacher's intentions to the actually achieved outcomes. For example, the researchers suggest that the teacher is introducing a story, which is a statement that can only be made if the story has actually happened. That is, rather than explaining how the outcomes are achieved, the researchers begin with the outcome-the story has happened-and, in teleological fashion, use what they wanted to explain (explanandum)-how a story begins and comes about in and through social interaction-to account for the actions that should be used in the explaining (explanans). Especially in fields such as education and educational psychology, (moral) judgments are made when the outcomes diverge from some norm. Researchers, from their theoretical and practical remove, often chastise teachers or students for not having done what they should have done in a fashion not unlike those unrealistically critiquing sports events from hindsight in an event form also known as "Monday morning quarterbacking." In the present instance, the story comes to be told and the researchers write about the teacher's "strategies" that lead to the "co-construction of educational narratives." Here, then, the occasional and situated production of a narrative comes to be expressed in terms of necessary and successful strategies that others might want to use to produce similar narratives (and the implied children's learning).

Monday morning quarterbacking and its equivalent in psychological research has the problem that it does not take into account the nature of practical actionwhich does not permit time out, knows no delay (Bourdieu, 1980). Any form of action, even a pause, is and becomes a resource for current and future actions. For example, if there was an extended pause unfolding following the statement "you told about now?" (turn 50), then it can (but does not have to) be heard as if Jessica (a) had not understood leading to a reiteration of a request in the same or different form, (b) unwillingness to respond, (c) inability to respond, and (d) in many other 
possible ways. If the event had unfolded as in Fragment 3, then the teacher's own continuation would provide hints as to how she has heard the unfolding pause. At the level of the conversation, the pause becomes a resource for attributing to the student a particular form of action or competence.

In "Mind the Border!", Marsico and Valsiner (in press) emphasize the need to consider boundaries for understanding developmental processes in psychology. Thus, the experienced present lies on that boundary between past and future; it is, as shown in Figure 1, simultaneously part of the past that begins and part of the still open future. Besides the characteristic of a boundary, a theory of developmental systems requires a "connection between the flow of time and the conditions of the border which are neither avoidable nor fixed." In music, the syncope refers to a situation where the harmony changes from one chord to another while one or more notes carry across. The syncope, therefore, is a figure of change across a boundary, integrating the boundary (between two chords) while making them hearable as different. Whereas the unsyncopated and syncopated parts do not appear to be identical, "they do, so to speak, cover the same semantic topology-but from different angles - for the syncopated pattern is heard 'with reference to,' 'in the light of,' as a remapping of, its partner" (Middleton, 1990, p. 210). In improvisational jazz, a "wrong" note may actually become an opportunity for a new developmental trajectory of a piece and, therefore, might not be a mistake at all but a mis-take that becomes the opportunity for a new take of the piece (Klemp et al., 2008). We can understand each individual turn in the preceding fragments as a syncope, belonging both to the past turn pair and the upcoming turn pair. This is consistent with the model in Figure 1b, where an actual statement constitutes the realization of one possibility from within the horizon of possibilities. Movement exists within the model as "realization of a possibility," and this movement is equivalent to a change from some probability $p<1$ to $p=1$. But, in a coincident opposite movement, the destruction of a possibility simultaneously opens up other possibilities.

\section{At the Interstices between Self and Other: Capturing Joint Activity as a Social- Psychological Fact}

[The interface is] defined not by the fact of their difference (in other words, not by a difference in outward [discernable by the subject] states between what is psychologically self and what is other ...) but by the single process of their mutual generation and mutual determination. (Mikhailov, 2001, pp. 2021 , original emphasis)

Analyses of verbal data tend to attribute words and statements to individuals (e.g., "the teacher prefaces ..."). That is, in this single move, both the identity of the person in flesh and the person in the narrative-subject of the sentence-as the cause of an action are presupposed. That is, although in fragments such as the ones featured here we observe relations at work and in progress, the analytic stance taken by many authors already reduce these relations to the interaction between individuals, each of whom becomes the cause (source) of actions. That is, with this 
move, analysts already commit to an ontology that no longer considers the interplay of self and other but in the separation of the two. Moreover, by using designations such as "the teacher," the analytical lens is narrowed to such an extent that it prevents researchers to take note of teaching | learning as an unfolding relation. The institutional position is thus conflated with the person who herself might be learning (as a teacher) by participating in and being exposed to the situation. Identities are fixed a priori to the relation rather than the result of the interface generating process that Mikhailov writes about in the opening quotation.

For psychologists such as L. S. Vygotsky or A. N. Leont'ev, higher psychological functions, consciousness, personality, and experience are the results of societal relations. In fact, these are not only the result of societal relations but also exist in and as societal relations. Thus, after the fact, "the relationship between higher psychological function was once a real relationship between people" (Vygotskij, 2005, p. 1021) and "social personality = the totality of societal relations embodied in the individual” (p. 1028). Society and societal facts, however, cannot be reduced to the individual (Durkheim, 1919). Social psychologists such as Leont'ev (1983), who founded cultural-historical activity theory, suggest using a minimum unit of analysis that retains all the properties of society: societal activity. This means that in the investigation of collective activity, such as conversation, to understand the inner dynamic of the phenomenon, we require units of analysis that retain their specifically collective character. Thus, for example, in a conversation, two turns may constitute one unit. Our Western languages, however, agent-centered as these are, generally do not have categories that capture the characteristically collective (social, societal) aspect of human relations. Psychological researchers tend to reduce a conversation to the input of individuals. Thus, statements and turns are attributed to the individual independently of the situational (contextual) constraints to which each agential (intentional) subject of activity is subject and subjected to.

We may be interested, for example, to understand the telling of a story as a joint (collective) activity, which means that even its beginning is jointly achieved. Once researchers make such a commitment, they need to have categories (units of analysis) that reflect the jointly-ness. Table 1 reproduces Fragment 1 but now takes each turn pair as an irreducible unit. Because we lack a language for joint action, each unit is denoted by a pair of mutually constitutive terms. The irreducibility of the pair is marked by means of a vertical bar ("|"). An "invitation | acceptance" is a joint action where each moment-i.e., invitation, acceptance-presupposes the other. Thus, an invitation is an invitation only because there is an acceptance, and an acceptance is an acceptance only because there is an invitation. Such an approach allows us to understand that the story actually does not get off the ground with turn pair I. In requesting to think about talking in a particular way ("so that it sounds now in here"), turn 3 also implies that turn 2 does not do what turn 3 states. The turn pair II therefore recognizes that something has been said but also that something else is to be done. Because turn 3 also belongs to turn pair III, it not only constitutes a backward link, by means of which a historical joint act comes to be completed, but also projects into the future. 
By choosing a form of analysis as described here, analysts obtain a conversation as a joint, collective, and self-moving phenomenon. It cannot be reduced to individual inputs. Moreover, this approach undermines the classical cause-effect figure applied to the analysis of conversations, where statements are attributed to the mental states of individuals, for example, as expressions of their knowledge, beliefs, affects, and so on. We cannot know what a statement does until we hear the next turn. Thus, if "Did you wash the dishes?" is paired with the statement "Why do you always have to nag?" we may have the seed for an argument or fight rather than a query concerning a state of affairs. There is now a historical fact of nagging that the conversation has to deal with.

The approach outlined thus far has methodological and theoretical consequences. Thus, for example, the original transcript uses the institutional designation "teacher." This may actually prevent researchers to focus on what is supposed to happen rather than what actually happens. For instance, analysts may not notice that teachers like the one featured in Fragments 1 and 2 get better at asking questions especially in those instances when some intended question does not lead to the intended response. Moreover, the common approach to analysis does not allow an understanding of a lesson as a joint achievement, which means that it fails to recognize that no lesson is under the complete control of the teacher consistent with the fact that the enacted curriculum differs from the planned curriculum (Remillard, 2005). This is apparent in the following lesson fragment, where, to use a gloss, Mrs. Turner asked "the same question" three times before Connor provided an acceptable and partially accepted response (Roth \& Radford, 2010).

The fragment derives from a second-grade mathematics lesson, the first one of what was planned as a 15-day (3-week) curriculum on 3-dimensional geometry. In this first lesson, students were asked to pull "mystery objects" from a black garbage back and then either place it with an existing category of objects on the floor or create a new category. In the course of the 22 students each taking a turn, a full classification of 22 object emerges. Connor, interacting with the teacher, comes to place his object with a set of others next to which the second teacher in the class has placed a label containing the words "cubes, squares."

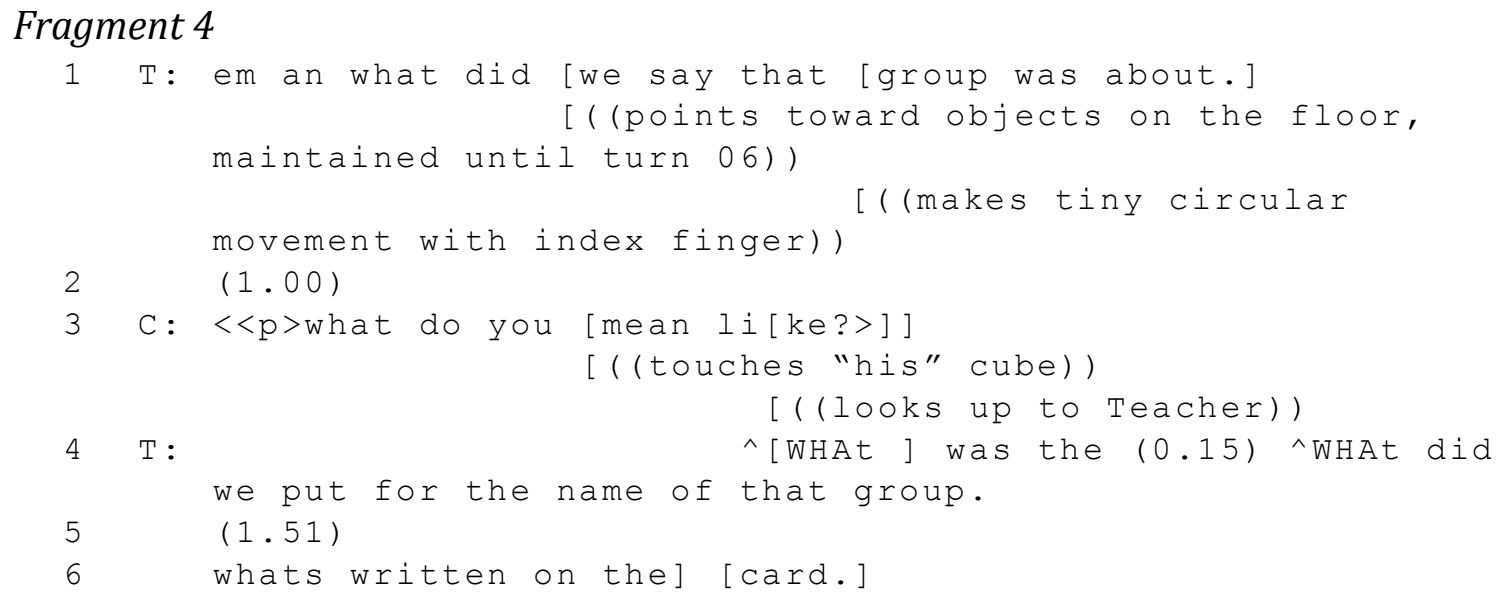


] [( Pulls hand back, no longer

By using a symmetrical approach, we can then see this fragment as one of those instances where teachers come to learn asking (age-appropriate) questions that lead to appropriate and acceptable next turn replies. In this situation Connor does eventually make a statement that constitutes a second-turn completion of a query about what had been written on a label next to one group of objects (turn 9). The boundaries between who is teaching and who is learning thereby come to be blurred. In fact, teaching and learning come to be situated in the societal relation and participation in classroom talk rather than being relegated to the grey matters of individuals. This form of analysis then is consistent with statements practice theorists make about "knowing and learning as engagement in changing processes of human activity" (Lave, 1993, p. 12).

In Fragment 4, we see that Connor actually contributes in an active way to the teacher's framing of an appropriate question that leads to the reply. In the pair turn 1 | turn 3, the semantic content of the first part of the pair comes to be an issue. In the second part of the next turn pair (turn 3 | turn 4), we find a transformed turn 1. We may gloss what is happening here as Connor assisting the teacher in coming to understand that the sense or purpose of turn 1 was not clear; turn 3 therefore can be heard as a request to clarify what the statement meant to say. In turn 4 and turn 6 , we find statements that say in different ways what turn 1 might have intended to say. That is, the query "What do you mean [to say]?" is followed by other, taken-tobe equivalent ways of saying something. That is, following turn 3, Mrs. Winter is producing-perhaps inventing, and, therefore, learning-other ways of articulating questions. Turn 2 can be heard as hesitation or delay, in which case it underscores the problematic nature of the statement in turn 1.

Endings, as beginnings, are the results of irreducibly joint action. We therefore require analytical tools to pick out the collective nature of this work. For example, the teacher might suggest that the end of a student's turn has arrived or request the student to sit down. But the end is in fact achieved when the student does not continue or sits down. The fact that in many school situations a student ends or sits down should not be taken as the absence of joint work. That there is work involved can be observed with "reticent students," such as the ones I encountered in schools serving predominantly students from poverty and working class situations. There, rather than stopping to speak loudly when requested, a student replied that he had to speak in this way because the teacher himself was too loud; and instead of taking off his cap when the principal who had arrived to deal with the situation asked him to do so, another student simply shook his head, and, as she asked him to leave, simply shook his head and the principal left the room without saying a word (Roth \& Tobin, 2002). In all those instances, what was achieved were invitation | rejections, and an end was achieved with a rejection | acceptance pair when the principal left 
the room. We learn from this that teachers' (or principals') intentions should not be taken as causal antecedents of classroom events.

Because of the particular stance taken to classroom talk, institutional positions tend to be used as explanans to explicate events rather than constituting the explananda. The researchers presenting Fragments 1 and 2 are led to conclude that the teacher orchestrated the talk, allowing students to remember and tell their stories. In these authors" analysis, the teacher became the actual author, thereby lending authority "of relating the personal events reported by the students to the overall narrative of the solubility of various foods." This apparently places the whole event on its head thereby completely neglecting that without the children there would not be a story at all. What is the joint work in which teaching and learning occur? Individuals may learn by the very fact that they participate in classroom talk rather than because someone else is teaching them. From the perspective of conversation as joint work, the ultimate text woven together in the give-and-take truly is a collective product rather than the sum of individual products (statements).

In the preceding paragraphs, I emphasize the need to go about the analysis in more symmetrical ways. This does not mean, however, that the institutionally designated teachers and students are equal. Instead, the participants in classroom events orient themselves and each other in such a way that differences in knowledge and (institutional) power come to be reproduced in and as relation. This is why experienced analysts easily identify teachers and students in completely blinded transcriptions (Roth \& Hsu, 2012). The analytic approach advocated here does in fact allow us to implement in which relations of power-knowledge "are to be analyzed ... not on the basis of a subject of knowledge who is or is not free in relation to the power system" (Foucault, 1975, p. 32). Instead, the analysis brings to relieve "the subject that knows, the objects to be known, and the modalities of knowledge" (p. 32), which are the effects of the mutually implicative relations that bind participants and settings into event-wholes.

\section{Discussion}

In the preceding sections, two dimensions of talk are worked out with concrete materials from actual conversations: (a) the temporal unfolding of talk within and between persons, always operating against an open horizon so that even the individual does not know with any perfect precision what she will have said when her saying comes to an end; (b) the simultaneous belonging of words to Self and Other, the precise constitution of whom is itself the result of a continuous coming and going. These two are orthogonal, diachronic and synchronic dimensions of human experience in talking (Roth, in press) that play themselves out at the crossroad of two bipolar infinities-i.e., past | future and inner | outer (Marsico \& Valsiner, in press). Theorizing the subject in terms of these two dimensions attributes to human intentionality its proper place: the human subject no longer is the sole determinant of action and social events but subject and subjected to its own actions as much as to those of others and the material world. Intentionality and agency thereby come to be paired with passibility and passivity, leading us to a 
more complete approach to theorizing and rendering human experience (e.g., Roth, 2011b).

In the preceding analyses, I heed the temporal unfolding of talk, which highlights that (a) speakers cannot know what they will have said until they have finished their saying and (b) the effect of a (speaker's) speech act is known only in, with, and through the reply. This helps us understand that what the preceding analyses revealed for the collective speaking - as embodied in Figure 1-also is the case for individual speaking. Thus, careful studies of individuals retelling stories or lecturing about scientific phenomena show how thinking unfolds with speaking and vice versa (McNeill, 2002). As a result, a physics professor might find that what he has said and elaborated for the past several minutes actually has to be wrong without knowing just what is wrong (Roth, 2012). Why would the professor consciously lecture a concept inconsistent with his field? We can understand what he did if we follow consider thinking and speaking as two processes that mediate each other (Vygotskij, 2005). It is not that speech constitutes something like a memory dump, where everything said is predetermined by some thought encoded in memory structures. Instead, thought develops in and with speaking, and speech develops in and with thinking. Much like Merleau-Ponty (1945), Vygotskij (2005) suggests that speakers find their thoughts in what they will have said: "The relation of thought to word above all is not a thing but a process - the movement from thought to word and reversely from word to thought" (p. 962). Thought begins with a first, vague seed and develops as speaking proceeds. Analyzing statements and turns at talk in terms of the external manifestation of an internal thought actually evacuates and conceals from understanding the future possible as possible. The method of reading transcripts exemplified here works against this prevalent practice.

The presented approach to data analysis also problematizes attributing statements to individual minds. This is so because each statement has an Other orientation in multiple ways. Each word or statement [vyskazivanie] is a replique, embodying within itself the word of the other who had spoken before (Vološinov, 1930). As shown above, the statement is shaped by the fact that it responds to a past statement and that it sets up a future statement (replique) to be produced by the other. Any statement draws on language that is not the speaker's own, but has come to her from the other; in speaking, language is produced for the other and, thereby, returns to the other (Derrida, 1996). Conducting the analysis of conversation in this way thereby actualizes the recommendation to investigate human behavior in terms transactions rather than interactions (Dewey \& Bentley, 1949/1999). In interaction, two or more independent entities come together in an exchange relation, where, in communication, some fixed signs come to be exchanged. In transaction, on the other hand, any identified part- "moment" in dialectical logic-depends on all other parts. Dewey and Bentley ask us to "consider ordinary everyday behaviors ... without subjection to either private mentalities or particulate mechanisms" (p. 141). Labels such as "the hunter" and "the hunted" make no sense independent of the cultural historical practice of "hunting." Similarly, labels such as "the teacher" and "the taught" ("learner") are correct only as consequences of participating in culturalhistorical practices. Proceeding in this manner then allows us to recognize instances when an institutionally designated "teacher" actually is a learner, and the 
institutionally designated "student" actually may be the teacher (Roth \& Radford, 2010).

Implicit in the examples provided here is that in conversation, participants do more than articulate content: they also produce and maintain the relation to which they are subject and subjected. For example, a particular kind of relation is entertained in by pair turn 3 lodged as it is between turns 2 and 4 of Fragment 1. Even if we had not information about the speakers but only had their spoken words, we would be able to narrow down our hypotheses with respect to the type of persons involved. That is, experienced analysts can recover a great deal when provided with an anonymized transcription-working in a manner not unlike Sherlock Holmes or Miss Marple-even if no external, background information is provided about specifying the who, when, where, or why of the unknown situation (Roth \& Hsu, 2012). As these authors suggest, analyzing transcriptions without any background information is a useful exercise for researchers in training, as this practice requires analysts to stay right at and close to the data. Moreover, focusing on carefully chosen relations allows us to study higher psychological processes, because the latter always exist first in the former (Vygotskij, 2005).

Once analysts take seriously that conversations are enabled by societal relations they are confronted with the need to work with supra-individual units of analysis and categories. Situations involving others always exceed individual intentions. A relation implies two or more individuals that cannot be thought independently, just as a handclap requires two hands and most dance forms require two. This approach, modeled in Figures $1 \mathrm{~b}$ and $1 \mathrm{c}$-i.e., the speech act as 2 circles connected by a solid line, the former linked to previous circles and the last figuring against an open horizon of possibilities - allows us to understand real events, such as how committees arrive at decisions that may not coincide with any of the options that the members had come with, or the evolution of a design in the course of the designing process. Thus, for example, one study explicitly described children's design activities in terms of virtual possibilities some of which come to be realized (Roth, 2001). The actual design path both constrained future options and opened up options that had not been considered before. In one instance, a group of students had decided to build an earthquake-proof tower. After they had built the modules, a second options for putting these together became apparent. By putting the smaller cube below the bigger one, the resulting tower would resemble the earth-quakeproof building of West Coast Energy (Vancouver). While implementing the actions that would lead them towards this design option, the students realized that what they had produced was more like "the leaning Tower of Pisa," which led them to consider further design options. They then decided to place their cubical modules on top of each other, at which point someone noted that the result would look like the "Empire State Building." Yet within two further building moves on their prototype, new options for their design became apparent. The next action put them en route toward a design that resembled, and was named, "The Eiffel Tower." Diagramming this evolution in the manner sketched in Figure 1c would show that with each concrete step taken, previous possibilities no longer were available (i.e., $p$ $=0$ ) or diminished, while new previously non-existing possibilities unpredictably and spontaneously emerged. The approach to the analysis of transcripts described 
here traces out this emergence and the historical trace without providing teleological explanations. Any psychological theory of designing needs to take this evolution before an open horizon into account.

The analytic approach presented here brings together what have been called the different constitutional dimensions of time (Tateo \& Marsico, 2013). Most immediately, there is an interweaving of micro-time, where we find the individual psychological experience of temporality, and meso-time, where we find the communicated and intersubjective experience of time. For example, the unfolding of a pause in turn 2 of Fragment 4, belongs to both participants, who give time (Mrs. Winter) and take time (Connor). When that time of this pause lengthens, Mrs. Winter might act as if it indicated further problems, such as following the pause in turn 5 (1.51 s), where she takes the next turn rephrasing the question yet another time. On the other hand, Connor might be considered to be taking his time, attempting to understand and finding the seed for an appropriate response. Time and temporality no longer are external to the event but are constituted there from within. The intersubjective time becomes a resource such that-depending on the next turn-attributions are made to the other as being slow or deliberate and thoughtful student, a sensitive teacher considerate of students' needs. As the classroom talk unfolds, in its characteristic of time and temporality, a societal event is produced with all its typical institutional relations between teachers and their students. It is also the place where language changes at the cultural-historical level, as postulated in sociological approaches to language (e.g., Vološinov, 1930) and in careful studies relating instantaneous, ontogenetic, and cultural changes of language (Roth, 2013a). Thus, it is out of such micro-genetic changes in very local contexts that new words and grammatical forms emerge (e.g., the verb "to google" following the appearance of Google). More importantly, time is irreversible, for the realization of possibilities produces a directionality that cannot be turned around. The reversal of any two turns would have produced a different form of joint action-e.g., Table 1, Figure 1 -rather than the same action in the reverse.

The analytic approach offered here undermines the validity of the classical cause-effect figure that underlies most current theories of human beings, for example, in theoretical concepts such as agency, positioning, stance taking, or knowledge construction. In all of these, the subject is the source (cause) of actions that bring about intended outcomes. However, the cause-effect figure underlying much of human reasoning-epitomized in technological thinking and constituting the essence of metaphysics (Heidegger, 2006) - obliterates the human experience of the openness of the future and participating in relations with others, neither of which is under our control. With the proposed approach to data analysis and conceptualization (Figure 1), we actually address a critique that process philosophers have launched against metaphysics. Thus, for example, Nietzsche (1954) points out that "the effect always is 'unconscious': the implied and imagined cause is projected, follows in time" (p. 472). Because we cannot know an effect of speech until it becomes evident-i.e., it is not yet something that we can be consciously aware of-causes (forces) that move a conversation can be attributed only after the fact. 
The preceding parts of this text exhibit and exemplify a particular approach to the analysis of talk-in-settings. I offer the approach not as a mere technique but as a way to practice a concrete human psychology that provides an interface between the grander philosophical themes and concrete human experience. Thus, for example, the close analytic attention to talk allows us to work out fundamental ethical questions in ways that have been foreshadowed in philosophical works (e.g., Bakhtin, 1993; Levinas, 1990) but that have not had its impact on empirical research and the practical settings that its results inform. For example, if the speaker cannot (completely) anticipate the future effects of her speech, then the upshot is that she is responsible without knowing what for; and if the recipient in part determines the nature of a speech act, he is responsible for something that he has not even effectuated (Roth, 2013c). This should have implications for how we rethink accountability and responsibility in the political and judicial arenas, where actions tend to be judged a posteriori and with hindsight rather than through the eyes of the subject facing an open future. Similar reversals can be anticipated to occur when we investigate, using the analytic apparatus, questions of power, (gender, race, socio-economic) inequities, colonialism, the function of institutions, the relations of cause and effect, or justice.

\section{References}

Andrée, M., Wickman, P.-O., \& Lager-Nyqvist, L. (in press). In R. Säljö, P. Linell, \& Å. Mäkitalo (Eds.), Memory practices and learning: Experiential, institutional, and sociocultural perspectives. "City: Publisher».

Bakhtin, M. M. (1993). Towards a philosophy of the act. Austin, TX: University of Texas Press.

Bergson, H. (1908). L'évolution créatrice [Creative evolution]. Paris, France: Félix Alcan et Guillaumin.

Bourdieu, P. (1980). Le sens pratique. Paris, France: Les Éditions de Minuit.

Derrida, J. (1996). Le monolinguisme de l'autre ou prothèse d'origine

[Monolingualism of the other or prosthesis of origin]. Paris, France: Galilée.

Dewey, J., \& Bentley, A. F. (1999). Knowing and the known. In R. Handy \& E. E.

Hardwood, Useful procedures of inquiry (pp. 97-209). Great Barrington, MA:

Behavioral Research Council. (First published in 1949)

Durkheim, E. (1919). Les règles de la méthode sociologique [Rules of sociological method]. Paris, France: Felix Alcan.

Foucault, M. (1975). Surveiller et punir: naissance de la prison [Discipline and punish: Birth of the prison]. Paris, France: Gallimard.

Heidegger, M. (1977). Sein und Zeit [Being and time]. Tübingen, Germany: Max Niemeyer.

Heidegger, M. (2006). Gesamtausgabe I. Abteilung: Veröffentlichte Schriften 19101976 Band 11. Identität und Differenz [Collected works, Division I: Published writings 1910-1976 vol 11. Identity and difference]. Frankfurt/M, Germany: Vittorio Klostermann. 
Klemp, N., McDermott, R., Raley, J., Thibeault, M., Powell, K., \& Levitin, D. J. (2008). Plans, takes, and mis-takes. Outlines: Critical Social Studies, 11 (1), 4-21.

Lave, J. (1993). The practice of learning. In S. Chaiklin \& J. Lave (Eds.), Understanding practice: Perspectives on activity and context (pp. 3-32). Cambridge, UK: Cambridge University Press.

Leont'ev, A. N. (1983). Dejatel'nost'. Soznanie. Ličnost'. [Activity, consciousness, personality]. In Izbrannye psixhologičeskie proizvedenija vol. 2 (pp. 94-231). Moscow, Russia: Pedagogika.

Levinas, É. (1990). Autrement qu'être ou au-delà de l'essence [Otherwise than being or beyond essence]. Paris, France: Librairie Générale Française.

Marsico, G., \& Valsiner, J. (in press). Mind the border! Experiencing the present and reconstructing the past through the boundaries. In R. Säljö, P. Linell, \& $\AA$. Mäkitalo (Eds.), Memory practices and learning: Experiential, institutional, and sociocultural perspectives. «City: Publisher».

Marx, K./Engels, F. (1958). Werke Band 3 [Works vol 3]. Berlin, Germany: Karl Dietz. McNeill, D. (2002). Gesture and language dialectic. Acta Linguistica Hafniensia, 34, 737.

Mead, G. H. (1932). The philosophy of the present. London, UK: Open Court.

Merleau-Ponty, M. (1945). Phénomenologie de la perception [Phenomenology of perception]. Paris, France: Gallimard.

Middleton (1990). Studying popular music. Philadelphia, PA: Open University Press.

Mikhailov, F. T. (2001). The "Other Within" for the psychologist. Journal of Russian and East European Psychology, 39(1), 6-31.

Nietzsche, F. (1954). Werke in drei Bänden Bd. 3 [Works in three volumes vol. 3]. Munich, Germany: Hanser.

Remillard, J. T. (2005). Examining key concepts in research on teachers' use of mathematics curricula. Review of Educational Research, 75, 211-246.

Romano, C. (1998). L'événement et le monde [Event and the world]. Paris, France: Presses Universitaires de France.

Roth, W.-M. (2001). Designing as distributed process. Learning and Instruction, 11, 211-239.

Roth, W.-M. (2011a). Geometry as objective science in elementary classrooms: Mathematics in the flesh. New York: Routledge.

Roth, W.-M. (2011b). Passibility: At the limits of the constructivist metaphor. Dordrecht, The Netherlands: Springer.

Roth, W.-M. (2012). Tracking the origins of signs in mathematical activity: A material phenomenological approach. In M. Bockarova, M. Danesi, \& R. Núñez (Eds.), Cognitive science and interdisciplinary approaches to mathematical cognition (pp. 182-215). Munich, Germany: LINCOM EUROPA.

Roth, W.-M. (2013a). Technology and science in classroom and interview talk with Swiss lower secondary school students: a Marxist sociological approach. Cultural Studies of Science Education, 8, 433-465.

Roth, W.-M. (2013b). To event: Towards a post-constructivist approach to theorizing and researching curriculum as event*-in-the-making. Curriculum Inquiry, 43, 388-417. 
Roth, W.-M. (2013c). Toward a post-constructivist ethics in/of teaching and learning. Pedagogies: An International Journal, 8, 103-125.

Roth, W.-M. (in press). Science language wanted alive: Through the dialectical/dialogical lens of Vygotsky and the Bakhtin circle. Journal of Research in Science Teaching.

Roth, W.-M., \& Hsu, P.-L. (2012). Analyzing verbal data: An object lesson. In B. J. Fraser, K. Tobin, \& C. McRobbie (Eds.), Second international handbook of science education (pp. 1501-1513). Dordrecht, The Netherlands: Springer-Verlag.

Roth, W.-M., \& Radford, L. (2010). Re/thinking the zone of proximal development (symmetrically). Mind, Culture, and Activity, 17, 299-307.

Roth, W.-M., \& Tobin, K. (2002). At the elbow of another: Learning to teach by coteaching. New York: Peter Lang.

Tateo, L., \& Marsico, G. (2013, May). Navigating the unknown river of development. Paper presented at the 15th meeting of the International Society for Theoretical Psychology, Santiago, Chile.

Vološinov, V. N. (1930). Marksizm i folosofija jazyka: osnovye problemy sociologičeskogo metoda b nauke o jazyke [Marxism and the philosophy of language: Main problems of the sociological method in linguistics]. Leningrad, USSR: Priboj.

Vygotskij, L. S. (2005). Psyxhologija razvitija čeloveka [Psychology of human development]. Moscow, Russia: Eksmo.

\section{Caption}

Figure 1. a. A turn at talk actually projects an open horizon of possible replies. b. A specific replay closes other possibilities to reply and constitutes a definite historical trace while opening up new possibilities for a future reply. c. Most analyses use the end point of a turn sequence and then explain the actual trace in terms of a cause-effect figure. 


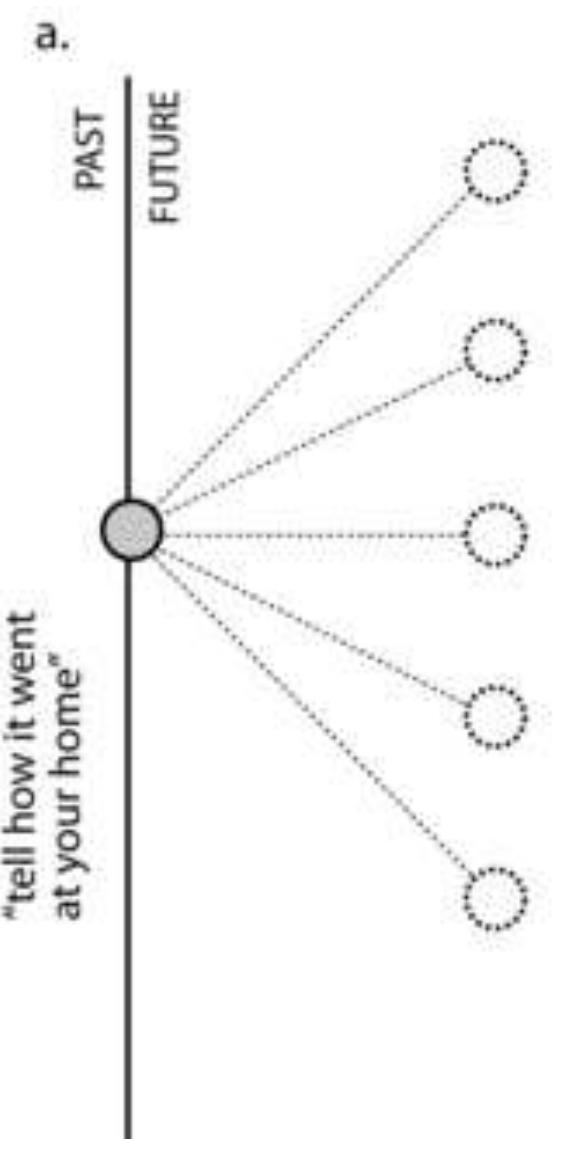

b.

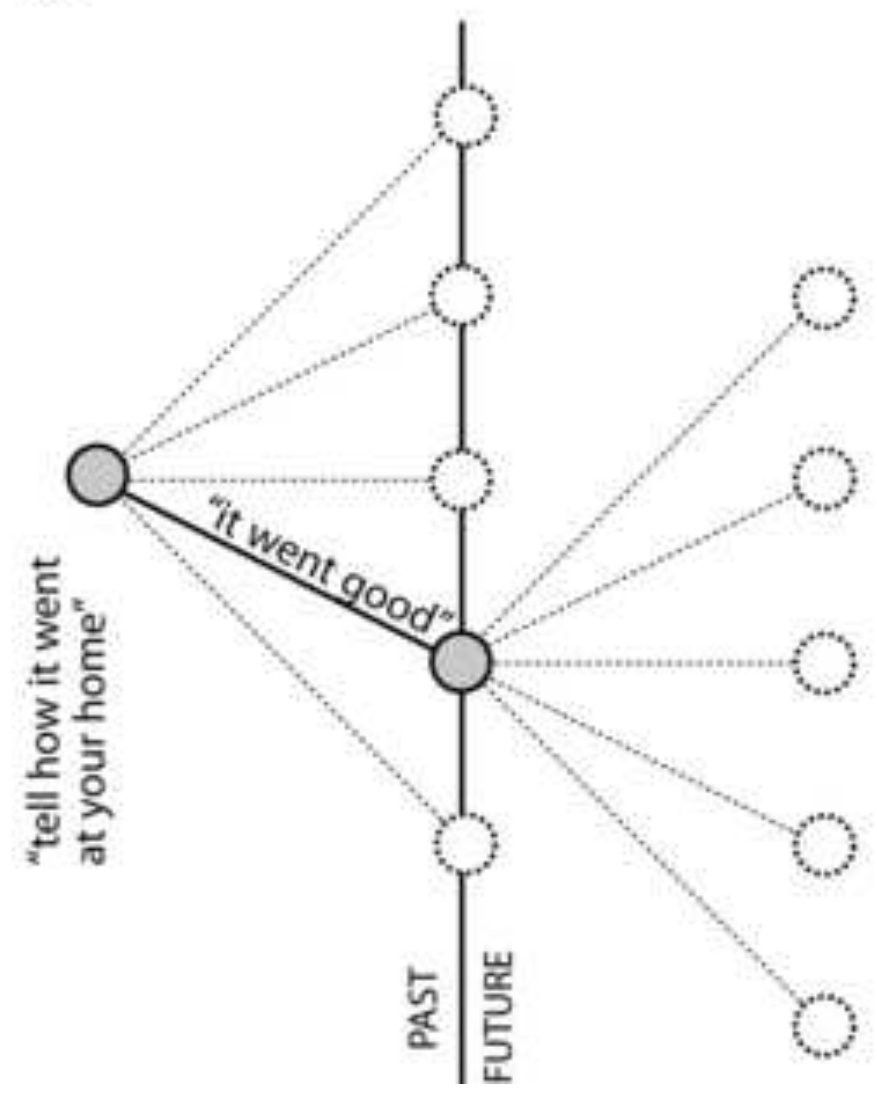

c.

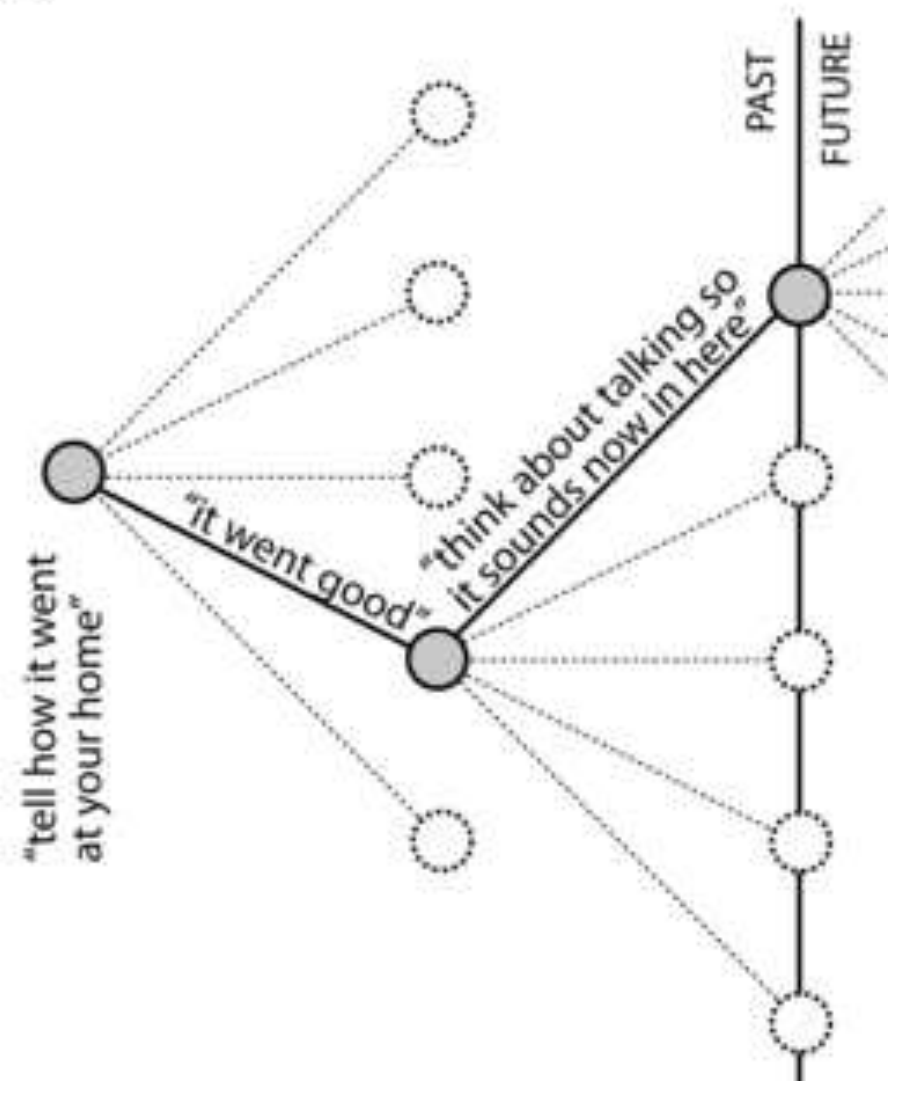


Table 1. Four turns constitute three units of joint, social action

\begin{tabular}{|l|l|}
\hline Transcript & $\begin{array}{l}\text { Joint, Social, } \\
\text { Conversational Action }\end{array}$ \\
\hline
\end{tabular}

1 Teacher: then I thought that we'd begin listening to Jessica. you're going to tell how it went at your home when you did your homework

2 Jessica: yes, it went like really good

\} $\begin{array}{ll}\text { INVITATION I } \\ \text { ACCEPTANCE }\end{array}$

$\left.\begin{array}{|lll|}2 & \text { Jessica: } & \text { yes, it went like really good } \\ 3 & \text { Teacher: } & \text { think about talking so that it sounds now } \\ & \text { in here }\end{array}\right\} \begin{aligned} & \text { OFFER | } \\ & \text { ACCEPTANCE, } \\ & \text { NEGATIVE } \\ & \text { EVALUATION }\end{aligned}$

$\left.\begin{array}{|ll}\text { Teacher: } \\ \text { think about talking so that it sounds now } \\ \text { in here } \\ \text { Jessica: }\end{array}\right\} \begin{aligned} & \text { REQUEST, } \\ & \text { INVITATION I } \mathrm{f} \text { food } \\ & \text { REPLY, } \\ & \text { ACCEPTANCE }\end{aligned}$

